\title{
The effects of threat of shock on SCR habituation to simple auditory stimuli
}

\author{
DOUGLAS CARROLL and JULIA POKORA \\ University of Birmingham, P. O. Box 363, Birmingham B15 2TT, England
}

\begin{abstract}
While the course of orienting response habituation has been examined in terms of physical properties of repeated stimuli, the effects of the tonic state of the individual have been largely ignored. The present study investigated the influence of threat of shock on habituation of the SCR to a series of simple auditory stimuli. Threatened subjects demonstrated slow SCR habituation and tonic SCLs resistant to decline compared to nonthreat subjects. These findings can be interpreted in terms of Bernstein's "significance hypothesis."
\end{abstract}

Recently, several investigators have stressed that elicitation and habituation of the phasic physiological components of the orienting response (OR) involve a complex interplay of the physical properties of the stimulus and the motivational and emotional involvement of the individual (Bernstein, 1969; Bernstein, 1973; Maltzman \& Mandell, 1968). However, whereas extensive experimental activity has to some extent elucidated the parameters of simple innocuous stimuli which affect the course of habituation (Sokolov, 1963), the effects of the tonic emotional state of an individual have not attracted systematic attention. In an attempt to remedy this lack of attention, Maltzman, Smith, Kantor, and Mandell (1971) exposed undergraduate and graduate psychology students to a series of innocuous visual and auditory stimuli on two occasions. Whereas the undergraduates showed more persistently large skin-conductance responses (SCRs) than the graduates to stimuli in the initial session, the reverse was true in the second session. Since, for the graduate students, this second session immediately preceded a stressful oral examination, Maltzman et al. concluded that the observed interaction reflected the influence of uncertainty and defensiveness on SCR habituation. Their result, however, was complicated by the observation that both groups demonstrated significantly smaller SCRs in the second session. Further, since the interval between sessions for the undergraduates was 4 weeks, as opposed to 9-10 weeks for the graduates, recency of previous testing might also have contributed substantially to their data. More extensive retention of habituation would be expected for the group with the shorter interval between testing sessions. While Maltzman et al.'s data on tonic cephalic vasomotor changes during the habituation series favor the defensiveness inter-

Requests for reprints should be sent to Douglas Carroll, Department of Psychology, University of Birmingham, P. O. Box 363, Elms Road, Birmingham B15 2TT, England. pretation, a much simpler design eliminating the problems of a two-session procedure, would undoubtedly clarify the nature of the effects of tonic emotional state on habituation. It is in this context that the present study investigated the effects of threat of impending shock on the course of SCR habituation to repeated simple auditory stimuli.

\section{METHOD}

Subjects were 12 male and 12 female first-year psychology students. Their mean age was 19.0 years, and, as far as could be determined by preliminary questioning, none of them suffered from any hearing defects.

The auditory stimuli were a series of $211,00-\mathrm{Hz} 75-\mathrm{dB}$ pure tones of 1-sec duration. Each subject received the same random temporal order of stimulus presentation; the interstimulus interval varying between 10 and $20 \mathrm{sec}$ with a mean of $15 \mathrm{sec}$. The tones were produced by a Farnell oscillator and presented through Akai headphones.

Skin conductance was recorded on a two-channel Beckman RS type dynograph using a Beckman SC coupler. $\mathrm{Ag} / \mathrm{AgCl}$ electrodes, $20 \mathrm{~mm}$ in diam, were attached over the distal phalanges of the second and third fingers of the left hand. Current across the electrodes was 15 microA. A $.5 \% \mathrm{NaCl}$ electrolyte was used with electrode attachments. The second dynograph channel provided an event marker.

Subjects were randomly assigned to one of two groups with the provision of equal sex representation. Subjects were tested individually in a sound-attenuated room. Following SC electrode attachment, each subject was presented with a single $100-\mathrm{dB}$ tone of 1 -sec duration. The subject was informed that this single presentation would "aid calibration of the equipment." An additional electrode was then attached to the subject's left ankle and the experimental instructions read. Subjects in the threat-of-shock group were informed that they would hear a series of moderate tones. They were instructed that, following the tone series, they might receive an electric shock via the ankle electrode. Shock delivery, it was stressed, would depend on the "particular physiological profile" that the subject demonstrated during presentation of the tone series. The exact nature of the profile that apparently determined shock occurrence was left unspecified. None of these threat-group subjects, in fact, received any shocks. Subjects in the second nonthreat group were given similar instructions. save that no mention was made of any electric shock possibility. The additional electrode was explained away as a "ground." Ten minutes were allowed for relaxation. Following presentation of the stimulus series, the subject was asked to check the item on the Jacob and Munz (1968) perceived stress index (PSI) which best described his/her feelings during tone presentation. 


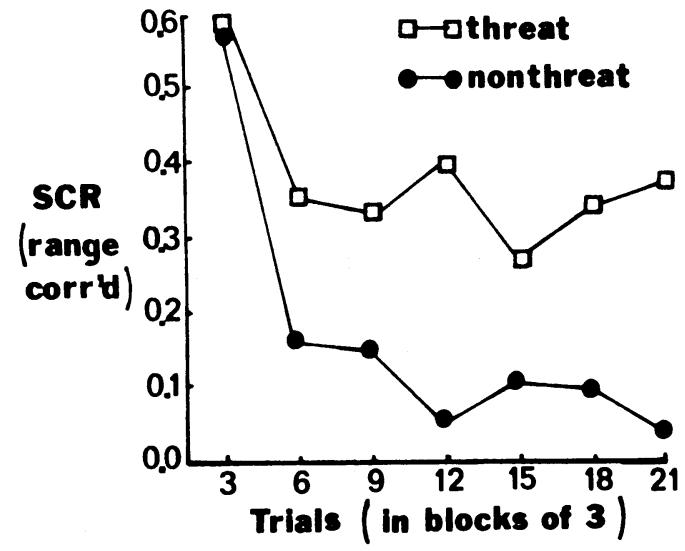

Figure 1. Mean range-corrected SCRs for threat and nonthreat subjects plotted for blocks of three stimulus presentations.

Decreases in skin resistance of 500 ohms or greater with a latency of 1 to $5 \mathrm{sec}$ after stimulus onset were scored as SCRs evoked by the stimulus. The resistance level immediately prior to tone onset and the minimum resistance level reached after tone onset were noted and transformed into reciprocal conductance units, yielding an SCR in micromhos. Using SCR amplitude to the initial $100 \mathrm{~dB}$ as representing an individual's maximum SCR, a range correction was applied to the SCR data, expressing each SCR as a proportion of the individual's maximum SCR. To compute range-corrected SCRs, then, the following formula was used:

$$
\Delta \phi i x=\frac{\text { SCRix }}{\text { SCRi(max) }},
$$

where $\Delta \phi i x$ is the SCR score corrected for individual differences in the range of SCR; SCRix is the SCR of the ith subject on the $x$ th trial of tone stimulation; SCRi(max) is the maximum SCR demonstrated by the ith subject (in this case the SCR elicited by a 100-dB tone). Lykken and Venables (1971) advise that this transformation "is the appropriate unit in which to express the SCR for comparing individuals."

\section{RESULTS}

The average range-corrected SCRs for the two groups for block of three stimulus presentations are shown in Figure 1. Analysis of variance provided statistical confirmation of the graphical impression. Highly significant trials $(F=20.07$, df $=20 / 440$, $\mathrm{p}<.001)$ and trials by groups $(\mathrm{F}=6.01$, $\mathrm{df}=20 / 440, p<.001)$ effects, indicated clearly that there was an overall change in SCR across trials and that the nature of this change differed substantially for the two groups. The F ratio for the overall groups comparison was not sufficiently large to be considered significantly improbable $(\mathrm{F}=3.51, \mathrm{df}=1 / 22$, $\mathrm{p}<.10)$. The same statistical comparisons were made on the uncorrected data, and the same significances obtained. A t test computed to compare the amplitude of the maximum SCRs for the two groups indicated that the groups did not differ significantly in this respect $(t=1.33)$.

The number of nonspecific SCRs emitted during the tone series was recorded. These nonspecific fluctuations were defined as phasic decreases in skin resistance of at least $500 \mathrm{ohms}$ not occurring within 1 to $5 \mathrm{sec}$ of stimulus onset. The mean number of such nonspecific SCRs was $15.8 \quad(\sigma=10.5)$ and $10.5(\sigma=11.5)$ for the threat and nonthreat groups, respectively. A t test revealed that the difference between values was not significant $(t=1.19)$.

Skin-conductance level (SCL) was sampled for each subject at $0,1.5,3$, and $4.5 \mathrm{~min}$ from a starting point $10 \mathrm{sec}$ prior to the delivery of the first tone in the habituation series. These SCL values are shown for each group in Figure 2. Analysis of variance indicated that SCL varied significantly with time $(F=5.87$, $\mathrm{df}=3 / 66, \mathrm{p}<.005$ ) and that the nature of this variation differed for the two groups $(F=3.33$, df $=3 / 66, p<.025)$. Inspection of Figure 2 indicates that whereas SCL shows a progressive decline with time for the nonthreat group, no such decline is apparent with the threat group. There was no significant overall difference between the two groups in SCL $(F=.02)$.

Mean rating intensity on the PSI was 6.50 for the threat group and 5.20 for the nonthreat group. This difference between these values was statistically significant $(t=2.38, \mathrm{df}=22, \mathrm{p}<.05)$. The most frequent category checked by subjects in the threat group was "uneasy." Nonthreat subjects generally preferred "at ease" or "all right" to describe their feelings during the habituation stimulus series.

\section{DISCUSSION}

The present results show clearly that the threat of an impending electric shock retards the rate of SCR habituation to simple auditory stimuli. This finding of resistance of the SCR to habituation in a situation in which the subject feels "uneasy," is in accord with the results of Maltzman et al. (1971). Both studies strongly suggest that the course of habituation of the SCR component of the OR is determined not only by the neural analysis and representation of the salient

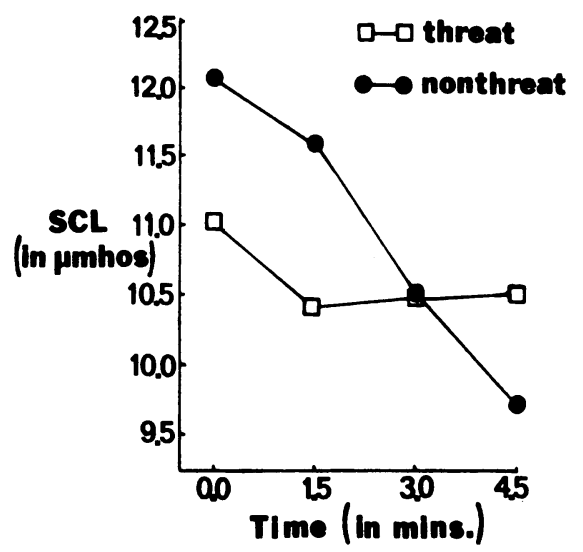

Figure 2. mean SCLs at sampling points for threat and nonthreat subjects. 
physical parameters of repetitive stimuli (Sokolov. 1963) but also by the tonic state of the individual. Tonic as well as phasic physiological differences between groups were apparent in the present experiment, the SCL of the threat group demonstrating a marked resistance to decline during the stimulus series.

However, any conclusion that the retarded habituation associated with shock threat is due to an increase in nonspecific tonic arousal must remain tentative. The present results can also be accounted for by inferring more specific arousal effects that reflect subjects' pairing tones with potential shock. the tones in fact being experienced as conditioned stimuli for the shock. In this connection, it must be emphasized that shock delivery was supposed to be contingent upon physiological response during the tone series. This latter interpretation allows the present data to be handled adequately by Sokolov's (1963) scheme. According to Sokolov, stimuli which have acquired extra significance by gaining signaling properties provoke ORs more resistant to habituation than simple stimuli that do not possess such significance, irrespective of considerations such as the improbability of the stimuli.

However, if the present results are construed in terms of the influence of nonspecific tonic arousal on OR habituation, they are difficult to incorporate into Sokolov's theory of OR elicitation and habituation and his strict dichotomy of stimuli into those possessing and those not possessing signal significance. Viewed in this light, the present data would seem to demand a representation in which analysis of stimulus significance is viewed as an integral part of the neuronal modeling process and not as a special case. Such a representation is offered by Bernstein (1969, 1973). According to Bernstein. the analytical process suggested by Sokolov, involving the assessment of how improbable a particular stimulus is. in terms of its physical aspects, is always followed by a second process where the significance of the stimulus for the individual is evaluated. Decisions about stimulus significance. Bernstein (1973) contends, are complex affairs involving "changes in the criteria with changing experience, changing mood or internal state." According to this formulation, then, although retarded SCR habituation in the shock-threat group does reflect an altered assessment of the tone series, this altered assessment stems from nonspecific changes in the tonic internal state associated with threat, and not from the tones being experienced as conditioned stimuli for shock.

Although the observation of tonic physiological differences between the two groups tends to favor interpretation in terms of nonspecific tonic arousal effects, a further experiment which aimed at inducing high arousal, unrelated to the stimuli comprising the habituation series, would undoubtedly clarify the issue.

\section{REFERENCES}

Bernstein. A. S. To what does the orienting response respond? Psychophysiology, 1969, 6. 338-350.

Bernstein, A. S. Electrodermal lability and the OR: Reply to $\mathrm{O}^{\prime}$ Gorman and further exposition of the "significance hypothesis." Australian Journal of Psychology, 1973, 25. 147-154.

JaCob, P. D., \& Munz, D. C. An index for measuring perceived stress in a college population. Journal of Psychology, 1968, 70. 9.15.

Lykken, D. T. \& Venables, P. H. Direct measurement of skin conductance: A proposal for standardization. Psychophysiology. 1971, 8, 656-672.

Maltzman, I., \& Mandell, M. P. The orienting reflex as a predictor of learning and performance. Journal of Experimental Research in Personality. 1968, 3, 99-106.

Maltzman, I., Smith, M. J., Kantor, W., \& Mandell, M. P. Effects of stress on habituation of the orienting reflex. Journal of Experimental Psychology. 1971, 87, 207-214.

Sokolov. E. N. Perception and the conditioned reflex. Oxford: Pergamon Press. 1963.

(Received for publication June 30, 1975; revision accepted September 9, 1975.) 